\title{
Technology research on safe and clean extraction and hole sealing of
}

\section{underground gas}

\author{
Sulong $\mathrm{Li}^{1,2, \text { a }}$, Jie Gao ${ }^{1, \mathrm{~b}}$, Ye Zhu ${ }^{1, \mathrm{c}}$, Tongmao Yang ${ }^{1, \mathrm{~d}}$, Wen Xue \\ ${ }^{1}$ School of mechanics \& civil engineering, China University of Mining and Technology (Beijing), \\ Beijing, 100083, China \\ ${ }^{2}$ Shanxi Coal Import \& Export Group Co., Ltd., Taiyuan, 030006, China \\ ${ }^{3}$ School of Soil and Water Conservation, Beijing Forestry University, Beijing, 100083, China

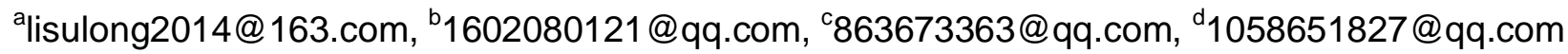

Key Words: Low permeability coal seam, gas extraction, polyurethane sealing hole, capsule bag-type high-pressure grouting sealing hole method

Abstract. Hongyuan Coal Mine belongs to low gas permeability coal seam, its permeability coefficient is lower than $0.1 \mathrm{~m}^{2} /(\mathrm{MPa} \bullet \mathrm{d})$, so the gas extraction will be difficult to do and the efficiency of extraction will be low, underground gas extraction has been using polyurethane to seal hole and this method exits a lot of problems. By studying the capsule bag-type high-pressure grouting sealing hole method of system feasibility, and applying it in site successfully, the paper solve problems exit in gas extraction of Hongyuan Coal Mine

\section{Introduction}

Hole sealing technology is a key point to solve the problem of gas extraction, The experimental study and Application of gas extraction Technology have a pressing reality and necessity [1-4], Hongyuan Coal Mine has made some breakthrough in leakage disposal technology of gas extraction which use capsule bag-type grouting sealing hole.

\section{General situation of coal Mine}

Hongyuan Coal Mine in Zuoquan belongs to Shanxi coal import and export group co., LTD. It is a resources integrating coal mine with designed production capacity $1.20 \mathrm{Mt} / \mathrm{a}$. The mine is located in Zuoquan county town $20 \mathrm{~km}$ north of Wangping village, Hanwang township which Administrative divisions under Hanwang township, ZuoQuan county town jurisdiction.

\section{Analysis of gas governance technology}

The main coal seam with joint fissures of Hongyuan coalmine is $15 \#$ coal seam, its gas content is $15.8 \mathrm{~m}^{3} / \mathrm{t}$, gas pressure is $0.68 \mathrm{Mpa}$ and coal seam permeability coefficient is $0.2 \mathrm{~m}^{2} /\left(\mathrm{MPa}^{2} \cdot \mathrm{d}\right)$. Gas extracting can be used in this coalmine, but it is hard to do. Hongyuan coalmine use polyurethane to sealing hole previously, the depth of the sealing hole is about $8 \mathrm{~m}$, with the common gas leakage of sealing hole and lack of concentration control and management, the underground gas's concentration of Hongyuan Coal Mine is very low which brought many problems, the performances are as follows.

Sealing hole leakage, which causes a low gas extracting concentration of 15\# coal, it not only hard to use mine gas and also waste a lot of gas resource. 
The gas density inside the pipeline is within explosion limits, so it affect the safety of the pipeline.

The leakage of sealing hole system greatly reduce the actual extraction negative pressure and affect the extraction efficiency and extraction effect.

In order to solve the above problem that hole sealing leakage and the low concentration of extraction, Hongyuan Coal Mine using active supporting type hole sealing technology in gas extraction.

\section{Capsule bag-type high-pressure grouting hole sealing technology}

Capsule bag-type high-pressure grouting hole sealing method. Compared with polymer foam materials hole sealing method and "two plugging and one injection" hole sealing method, it has a great improvement in hole sealing effect. Capsule bag-type high-pressure grouting hole sealing principle and method are shown in Fig. 1.

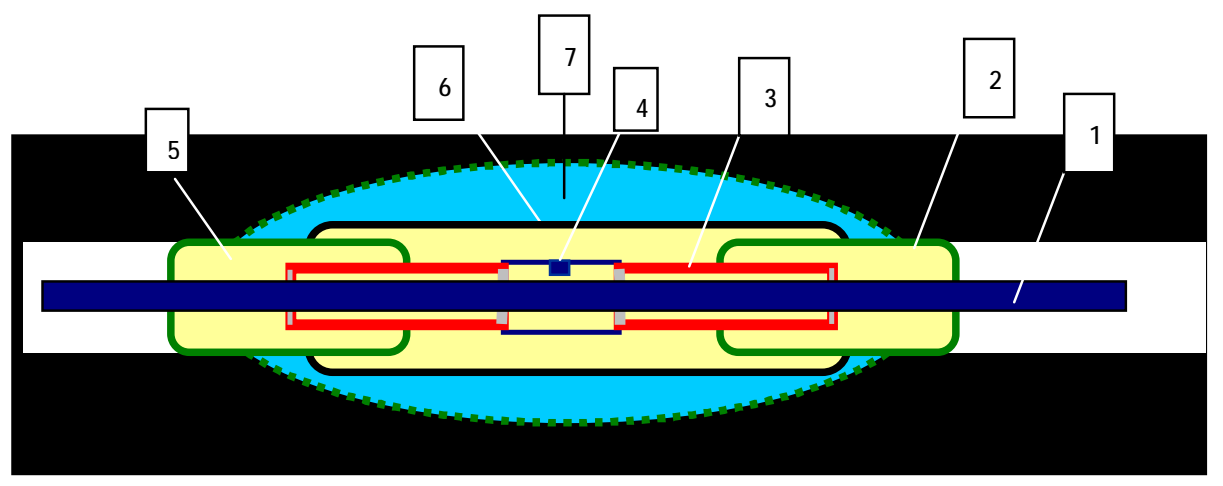

Fig. 1 Capsule bag grouting hole packer principle diagram

(1. The gas extraction tube, 2. Composite capsule bag, 3. Capsule bag inlet pulp channel, 4. Drilling given Pulp valve, 5. Cement cylinder, 6.Drilling fracture filling expansion area, 7. High stress area)

Capsule bag type grouting hole sealing method mechanism is shown in Fig. 2 and Fig. 3. Fig. 2 shows that red arrow represents pulp out by grouting slurry head after pouch out of the plasma channel into the pouch, makes the capsule bag expanding which can reach $240 \mathrm{~mm}$ on diameter, so it can makes a fully contact with the coal wall and block leakage channel, in the meantime it can support the drilling

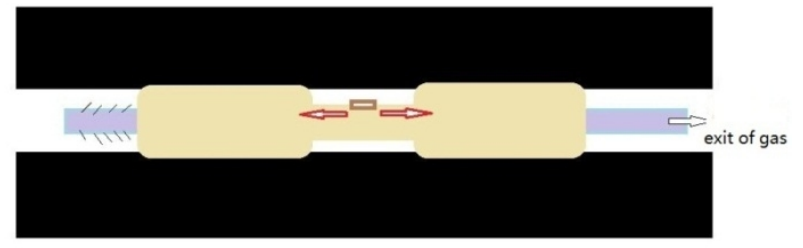

Fig. 2 The 1st time given pulp

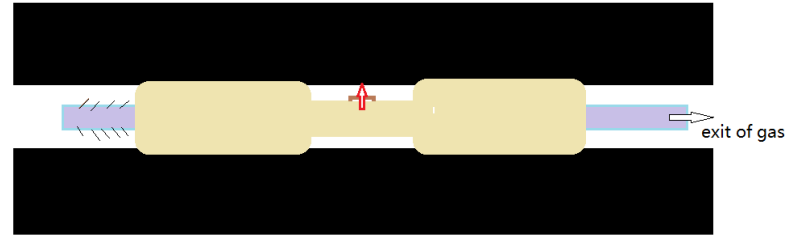

Fig. 3 The 2nd time given pulp

Fig. 3 shows that red arrow represents the channel of secondary pulp outing. When the first grouting reach $10 \mathrm{~kg} / \mathrm{cm}^{2}$, drilling giving pulp valve (an unidirectional valve) will automatically open, slurry inject into the pore between the coal wall. Because the capsule bag in two ends are plugging, slurry between the two bags will directly contact with coal wall in theory, this grouting segment can achieve more than $20 \mathrm{~kg} / \mathrm{cm}^{2}$.

The advantage of Capsule bag sealing hole opener. Compared with Polymer foam materials hole sealing method and "two plugging and one injection" hole sealing method, capsule bag-type high-pressure grouting hole sealing method has the following advantages.

It can grout drilling wall and plug early air leakage fracture .Firstly, let slurry grout into capsule bag which can plugging drilling of hole sealing segment, and then the slurry inside the bag will 
grout into drilling wall, this realize grouting the drilling of hole sealing segment through the ingenious device (grouting capsule bag), it solve the problem which people do not work out for years that grouting sealing hole in arbitrary angle. When grouting, slurry will plugging the fracture around the drilling under the effect of grouting pressure which will play a role in plugging the early air leakage channel.

Supporting the drilling actively, forming a high stress area around the drilling of hole sealing segment. Grouting material use expansive material but not foaming material, after initial setting the volume of grouting material will expand, the expansive force can approach ground stress which will form a high stress area around the drilling of hole sealing segment. it is shown in Fig. 4. Expansive force continue compact the unfilled fracture so that reduce the air leakage channel further. Expansion force can decrease the coal gas permeability of hole sealing segment (The higher the stress of coal, the worse the permeability of coal.)

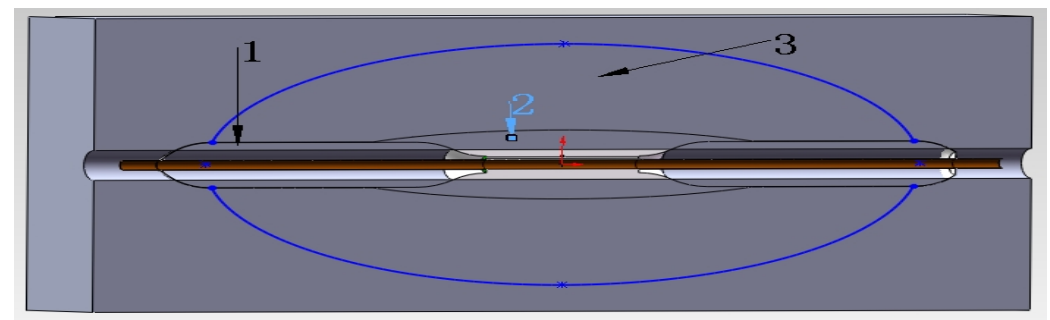

Fig. 4 Active supporting type hole sealing mechanism

(1.drilling fracture filling area, 2. Expansive cement cylinder, 3.high stress area.)

It can effectively increase the concentration of extraction. Capsule bag grouting hole sealing method can not only fill the fracture around the drilling well and eliminate the leakage channel left from opening hole, but also support the drilling reliably and confirm its stability, around the drilling won't produce new leakage channel, so the concentration of gas will promote effectively. It is shown in Fig. 5.

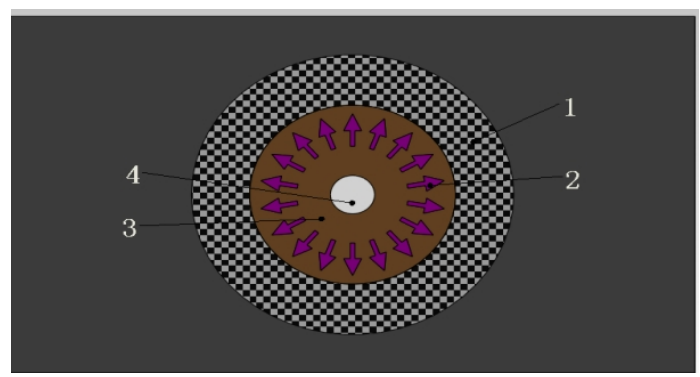

Fig. 5 The mechanism schematic diagram of hole sealing which filling the fracture and active support the drilling

(1.fracture filled area, 2.expansive supporting force, 3.Expansive concrete column, 4. hole sealing extraction tube.)

\section{Analysis of field application}

Experimental location profile. The experimental location of capsule bag grouting hole sealing method is in 150103 transportation belt lane of Hongyuan Coal Mine. The thickness of coal seam is 2.08-5.46 mean $4.28 \mathrm{~m}$, coal seam dip angle is $6^{\circ}$, the content of Gas is $10.43-12.12 \mathrm{~m}^{3} / \mathrm{t}$, and the gas pressure is $0.47-0.89 \mathrm{Mpa}$, the porosity of coal seam is $7.8-9.1 \%$, recoverable length on trend is $518 \mathrm{~m}$, inclination length is $150 \mathrm{~m}$, the absolute outflow of gas is in amount of $53.18 \mathrm{~m}^{3} / \mathrm{min}$, relative gas emission rate is $21.06 \mathrm{~m}^{3} / \mathrm{t}$, the permeability of Coal seam is low, its permeability coefficient is below $0.1 \mathrm{~m}^{2} /(\mathrm{MPa} \cdot \mathrm{d})$, it belongs to high-gas coalmine. The depth of drilling hole sealing in this experiment is $21 \mathrm{~m}$. 
Effect analysis. In this experiment the total number of hole sealing is 245 and involved roadway has $600 \mathrm{~m}$ in length of hole sealing construction. To ensure the seal is in good condition, the orifice need to be processed after sealing the hole. Using computer to analyses the average gas concentration in drilling, we can get the follow conclusion: (1) In three months after the hole sealing, the average concentration of drilling gas in 1\#-31\# will float around $70 \%$ and it keep stable on the whole which is expected to continue to maintain a period of time. (2) In two months after hole sealing, the average concentration of drilling gas in 32\#-75\# will maintain around $80 \%$ stably, and in a long time won't has any change. (3) In two months after hole sealing the average concentration of drilling gas in $132 \#-177 \#$ will maintain around $76 \%$ stably, and in a long time won't has any change. (4) In one month after hole sealing the average concentration of drilling gas in 76\#-131\# and 178\#-254\# will maintain above $76 \%$ stably, the average concentration of drilling gas all over $50 \%$ and above $25 \%$ for the single one. The experiment improves the serious problems of hole sealing leakage and low concentration of gas extraction in coal seam by applying the capsule bag grouting hole sealing technique to the practice. It will not only fill the fracture around the drilling well and eliminate the leakage channel left from opening hole, but also support the drilling reliably and confirm its stability, around the drilling, there won't produce new leakage channel which ensure the negative pressure of extraction needed in the actual .during the experiment, Grouting pressure can be increased from the original $10 \mathrm{~kg} / \mathrm{cm}^{2}$ to $15 \mathrm{~kg} / \mathrm{cm}^{2}$ which greatly increased the negative pressure inside the hole, thus Improve the efficiency and effect of the extraction.

\section{Conclusions}

Hongyuan Coal Mine use the capsule bag hole sealing method to seal hole in 150103 haulage gate has made a grate breakthrough in the key technology of underground gas's clean and safe extraction. By improve hole sealing technology, it keep the concentration of gas in drilling over $50 \%$ which improve the effect of extraction and ensure the safe transportation, this is a benign development through extraction to ensure safety.

The superiority of grouting hole sealing technology is verified by industrial experiment, capsule bag type grouting hole sealing device system is a novel structure and an ingenious conception. it can conduct on filed construction smoothly, and the hole sealing effect significantly improved. it Is one of the effective methods to improve the concentration of gas extraction in coal seam and laid a good foundation for the popularization of this technology.

\section{References:}

[1] Fuwang Zhang, Fuheng Fan, Ruxiang Qing. The Application that Capsule Bag-type "Two Plugging and One Injection" Hole Sealing Method Device Used in Gas Extraction of Drill Holes Along Seam [J]. Coal Engineering, 2013, (11): 57-59.

[2] Ji Li. The Experimental Research on Safety Performance of Hard Polyurethane Sealing Hole in Coalmine [D]. Beijing: China University Of Geosciences, 2011.

[3] Longshan Wu. Technology Research on Underground Gas Extraction in Negative Condition and Hole Sealing [J]. Shanxi Coal, 2011, 31(11): 53-56.

[4] Peiliang Ma. Prevention and Control Technical Manuals of Gas Disaster in Coal Mine [M]. Beijing: Chemical industry press, 2007. 